\title{
Association High-Iodine-Containing Seaweed Soup Consumption after Birth and Subclinical Hypothyroidism in Korean Women: Korea National Health and Nutrition Examination Survey IV (2013-2015)
}

\author{
Hyunsam $\mathrm{Kim}^{1}$, Ha $\mathrm{Ni} \mathrm{Lee}^{2}$ and Jeonghoon $\mathrm{Ha}^{1}$
}

Division of Endocrinology and Metabolism, Department of Internal Medicine, Seoul St. Mary's Hospital, College of Medicine, The Catholic University of Korea ${ }^{1}$, Seoul, Health Promotion Center, Department of Internal Medicine, Bobath Memorial Hospital ${ }^{2}$, Seongnam, Korea

Background and Objectives: This study was to investigate the association between the previous history of seaweed intake after childbirth and subclinical hypothyroidism (SCH) occurrence in Korean women based on the latest nationally representative epidemiological survey data, the Sixth Korea National Health and Nutrition Examination Survey (KNHANES VI). Materials and Methods: This study used data from KNHANES VI, a cross-sectional, nationally representative survey that comprises a health interview survey, health examination survey, and nutrition survey. Of the initial 22,948 Korean participants enrolled in KNHANES VI, 2,046 women were selected for this analysis. To examine $\mathrm{SCH}$, the thyroid-stimulating hormone (TSH) reference range was defined using a population-based TSH range. Results: Subclinical hypothyroidism was increased in those who consumed seaweed soup after childbirth, but this was not significant (OR 1.3, Cl: 0.80-2.13, p=0.293). However, the odd ratio for $\mathrm{SCH}$ differed according to the duration of seaweed soup consumption. When seaweed soup was consumed within 1 week after birth, the OR was increased in the crude model (OR 2.61, Cl: 1.39-4.89, $p=0.002$ ), but this was no longer significant in the adjusted model (OR 1.89, Cl: 0.79-4.50). Conclusion: The notable finding from this study is that the previous history of excessive seaweed consumption during post-partum period may not be a risk factor for $\mathrm{SCH}$ in Korean women.

Key Words: Subclinical hypothyroidism, lodine, Seaweed

\section{Introduction}

Subclinical hypothyroidism ( $\mathrm{SCH}$ ) is defined as an isolated elevated serum thyrotropin level despite a normal serum thyroid hormone level. ${ }^{1)}$ The prevalence of $\mathrm{SCH}$ ranges from $3 \%$ to $12 \%^{2,3)}$ and can be up to $20 \%$ in women older than 60 years. ${ }^{4)}$ The prevalence is dependent on the thyroid-stimulating hormone (TSH) reference range used, and the TSH level is strongly influenced by sex, area of residence, iodine intake, and presence of autoantibodies. ${ }^{2,5,6)}$ A prevalence of $\mathrm{SCH}$ up to $18 \%$ has been reported in iodine-rich areas, ${ }^{7,8)}$ and Korea is classified as an iodine-rich area. A previous study reported that the average iodine intake of healthy adults in Korea is 479

Received February 1l, 2019 / Revised July 5, 2019 / Accepted July 8, 2019

Correspondence: Jeonghoon Ha, MD, Division of Endocrinology and Metabolism, Department of Internal Medicine, Seoul St. Mary's Hospital, College of Medicine, The Catholic University of Korea, 222 Banpo-daero, Seocho-gu, Seoul O659l, Korea

Tel: 82-2-2258-6372, Fax: 82-2-599-3589, E-mail: 3002041@catholic.ac.kr

Copyright (c) 2019, the Korean Thyroid Association. All rights reserved.

(c) This is an open-access article distributed under the terms of the Creative Commons Attribution Non-Commercial License (http://creativecommons.org/licenses/by-nc/4.0/), which permits unrestricted non-commercial use, distribution, and reproduction in any medium, provided the original work is properly cited. 
$\mu \mathrm{g} /$ day and that the average urinary iodine concentration (UIC) is $674 \mu \mathrm{g} / \mathrm{g}$ creatinine. ${ }^{9)}$ Given that more than $500 \mu \mathrm{g} / \mathrm{g}$ creatinine of the UIC is considered to indicate excessive iodine intake, ${ }^{10}$ Korea is a high iodine-intake area. ${ }^{11)}$ This high intake may reflect the frequent nationwide dietary intake of iodine-rich seaweeds such as laver and kelp. ${ }^{11)}$ In Korea, it is a tradition for a mother to consume seaweed soup after childbirth to increase breast milk supply. The purposes of this study were to investigate the association between the previous history of seaweed intake after childbirth and $\mathrm{SCH}$ occurrence in Korean women based on the latest nationally representative epidemiological survey data, the Sixth Korea National Health and Nutrition Examination Survey (KNHANES VI).

\section{Materials and Methods}

\section{Study Population}

KNHANES VI was performed by the Korea Centers for Disease Control and Prevention (CDC) and comprises a health interview survey, health examination survey, and nutrition survey. It uses a stratified multistage probability sampling design. Informed written consent for participation was obtained from all study participants. The study was approved by the Korea CDC Institutional Review Board.

The TSH reference range was calculated based on the enrolled population, and the values corresponding to $2.5^{\text {th }}$ and $97.5^{\text {th }}$ percentiles were defined as reference ranges $(0.62-6.68 \mu \mathrm{UU} / \mathrm{mL})$. Of the initial 22,948 Korean participants, 2,046 women were selected for this analysis by excluding those who did not meet the inclusion criteria: male gender $(n=10,411)$, age $<19$ years $(n=2,338)$, pregnant $(n=16)$, history of delivery within 1 year $(n=96)$, history of treatment for thyroid disease $(n=71)$, insufficient urine iodine data ( $n=390)$, insufficient serum free thyroxine (FT4) data or FT4 level not within the normal range $(n=7,345)$, or insufficient TSH data or concentration $<0.62 \mu \mathrm{U} / \mathrm{mL}(\mathrm{n}=235)$.

\section{Measurements}

All measurements and data from questionnaires were collected by specially trained investigators. Detailed anthropometric measurements were made as in previous studies. ${ }^{12-14)}$ Creatinine, TSH, FT4 were measured in blood collected after overnight fasting. TSH concentration was measured using an E-TSH kit (Roche Diagnostics). FT4 concentration was measured using an E-Free T4 kit (Roche Diagnostics) for which the reference range was $0.89-1.76 \mathrm{ng} / \mathrm{mL}$. Clinical practice guidelines suggest the use of population-based reference ranges for $\mathrm{TSH}^{15}{ }^{15}$ In the present study, the range $0.62-6.68 \mu \mathrm{\mu U} / \mathrm{mL}$, which corresponds to the $2.5^{\text {th }}$ to $97.5^{\text {th }}$ percentiles of serum TSH concentration in the studied population, was used to define $\mathrm{SCH}$. lodine-intake status was evaluated using the urine iodine/creatinine ratio determined using inductively coupled plasma-mass spectrometry (PerkinEImer; Waltham, MA, USA). The duration of ingestion of seaweed soup after birth was classified as 1 week, 2 weeks, 3 weeks, 1 month, 2 months, and more than 2 months after birth.

\section{Statistical Analysis}

Statistical analyses were performed using SAS version 9.3 (SAS Institute, Cary, NC, USA). P-values $<0.05$ were significant. The data are expressed as number and percentage or as mean \pm standard deviation. Differences between participants with $\mathrm{SCH}$ and without $\mathrm{SCH}$ were evaluated using the Wilcoxon rank-sum test or the $\chi^{2}$ test, as appropriate. Differences between the four quartiles of serum TSH concentration were identified using a generalized linear model (Duncan's test of multiple comparisons). Multivariable adjusted logistic regression analysis was conducted to determine odds ratios (ORs) and 95\% confidence intervals $(\mathrm{Cls})$ for the risk of $\mathrm{SCH}$ across variables. Because of the complex sampling design, a weighted sampling method was used to assign participants representative of the Korean population in the analysis of data. Detailed characteristics of the statistical analysis of KNHANES have been reported previously. ${ }^{13,14)}$

\section{Results}

The characteristics of the study population are 
Table 1. Characteristics of study population*

\begin{tabular}{|c|c|c|c|c|}
\hline & \multirow{2}{*}{$\begin{array}{l}\text { Total subjects } \\
\quad(n=2046)\end{array}$} & \multicolumn{2}{|c|}{ Subclinical hypothyroidism } & \multirow{2}{*}{$\mathrm{p}$ value } \\
\hline & & No $(n=1938)$ & Yes $(n=108)$ & \\
\hline Age (years) & & & & 0.041 \\
\hline $19-29$ & 432 (19.3\%) & $414(21.4 \%)$ & $18(16.7 \%)$ & \\
\hline $30-39$ & $364(16.3 \%)$ & $349(18.0 \%)$ & $15(13.9 \%)$ & \\
\hline $40-49$ & $393(19.6 \%)$ & $374(19.3 \%)$ & $19(17.6 \%)$ & \\
\hline $50-59$ & $448(20.5 \%)$ & $413(21.3 \%)$ & $35(32.4 \%)$ & \\
\hline $60-69$ & $371(22.0 \%)$ & $355(18.3 \%)$ & $16(14.8 \%)$ & \\
\hline $70-$ & $38(2.3 \%)$ & $33(1.7 \%)$ & $5(4.6 \%)$ & \\
\hline Anti-TPO Ab & & & & $<0.001$ \\
\hline Absence & $1860(88.3 \%)$ & $1778(91.7 \%)$ & $82(75.9 \%)$ & \\
\hline Presence & $186(11.7 \%)$ & $160(8.3 \%)$ & $26(24.1 \%)$ & \\
\hline $\mathrm{UICR}^{\dagger}$ & & & & 0.019 \\
\hline Quartile 1 & $514(25.1 \%)$ & 502 (25.9\%) & $12(11.1 \%)$ & \\
\hline Quartile 2 & $520(25.4 \%)$ & 495 (25.5\%) & $25(23.2 \%)$ & \\
\hline Quartile 3 & $519(25.4 \%)$ & $488(25.2 \%)$ & $31(28.7 \%)$ & \\
\hline Quartile 4 & $493(24.1 \%)$ & $453(23.4 \%)$ & $40(37.0 \%)$ & \\
\hline $\begin{array}{l}\text { Intake of seaweed soup after } \\
\text { delivery }\end{array}$ & & & & 0.291 \\
\hline No & 595 (29.1\%) & $566(29.2 \%)$ & $29(26.9 \%)$ & \\
\hline Yes & $1451(70.9 \%)$ & $1372(70.8 \%)$ & $79(73.1 \%)$ & \\
\hline $\begin{array}{l}\text { Duration of seaweed soup } \\
\text { consumption after childbirth }\end{array}$ & & & & 0.003 \\
\hline Less than 1 week & $595(29.1 \%)$ & $566(29.2 \%)$ & $29(26.8 \%)$ & \\
\hline 1 week & $271(13.2 \%)$ & 247 (12.7\%) & $24(22.2 \%)$ & \\
\hline $1-2$ weeks & $344(16.8 \%)$ & 324 (16.7\%) & $20(18.5 \%)$ & \\
\hline 2-3 weeks & $304(14.9 \%)$ & $293(15.1 \%)$ & $11(10.2 \%)$ & \\
\hline 3-4 weeks & 449 (21.9\%) & $429(22.1 \%)$ & $20(18.5 \%)$ & \\
\hline $4-8$ weeks & $53(2.6 \%)$ & $51(2.6 \%)$ & $2(1.9 \%)$ & \\
\hline More than 8 weeks & $30(1.5 \%)$ & $28(1.6 \%)$ & $2(1.9 \%)$ & \\
\hline
\end{tabular}

${ }^{*}$ Data are presented as mean \pm SD, $n$ (weighted \%), Statistics were carried out using Rao-Scott Chi-square test; ${ }^{\dagger}$ lodine intake status was evaluated by urine iodine creatinine ratio, UICR, Quartile 1: $<$ Q1 (141.5), Quartile 2: $\geq Q 1$ and $<Q 2$ (281.8), Quartile 3: $\geq Q 2$ and $<Q 3$ (664.6), Quartile 4: $\geq Q 3$.

SD: standard deviation

shown in Table 1. Of the total 2,046 Korean women included, 108 (5.28\%) were confirmed to have $\mathrm{SCH}$. Participants with $\mathrm{SCH}$ were more likely to be older. Of those with $\mathrm{SCH}, 51.8 \%$ were aged $>50$ years, and $4.6 \%$ were aged $>70$ years. The median TSH concentration was highest $(2.66 \mu \mathrm{U} / \mathrm{mL})$ in the $>70-$ year age group (Supplementary Table 1). TPOAb was detected in 26 (24.1\%) participants with SCH. The urine iodine creatinine ratio (UICR) was uniformly distributed in the non-SCH group, whereas more participants fell within in the higher UICR quartile in the $\mathrm{SCH}$ group. It was found that $70.9 \%$ of Korean women consumed seaweed soup for more than one week after childbirth. The remaining $29.1 \%$ were found to not consume seaweed soup at all or consume seaweed soup for less than one week after childbirth. Participants who consumed seaweed soup for more than one week after childbirth mostly consumed seaweed soup for up to 3 to 4 weeks after childbirth (21.9\%). The $\mathrm{SCH}$ group most often consumed seaweed soup in the first week after childbirth, and the non-SCH group for up to 3 to 4 weeks after childbirth.

The OR for $\mathrm{SCH}$ was increased in those who consumed seaweed soup after childbirth, but this was not significant (OR 1.3, Cl: 0.80-2.13, p=0.293) (Table 2). The ORs for $\mathrm{SCH}$ differed according to the duration of seaweed soup consumption. When seaweed soup 


\section{Seaweed Soup and Subclinical Hypothyroidism}

Table 2. Logistic regression analysis of subjects with subclinical hypothyroidism*

\begin{tabular}{|c|c|c|c|c|}
\hline & \multicolumn{2}{|c|}{ Crude model } & \multicolumn{2}{|c|}{ Adjusted model } \\
\hline & Odds ratio $(95 \% \mathrm{Cl})$ & $p$ value & Odds ratio $(95 \% \mathrm{Cl})$ & $p$ value \\
\hline \multicolumn{5}{|l|}{ Age (years) } \\
\hline $19-29$ & Reference & & Reference & \\
\hline $30-39$ & $0.86(0.37-2.01)$ & 0.162 & $0.67(0.28-1.63)$ & 0.379 \\
\hline $40-49$ & $1.60(0.75-3.44)$ & 0.487 & $1.17(0.53-2.59)$ & 0.694 \\
\hline $50-59$ & $2.74(1.28-5.88)$ & 0.002 & $1.68(0.76-3.74)$ & 0.202 \\
\hline $60-69$ & $1.19(0.49-2.85)$ & 0.668 & $0.73(0.28-1.89)$ & 0.519 \\
\hline $70-$ & $1.31(0.33-5.20)$ & 0.963 & $0.97(0.25-3.69)$ & 0.960 \\
\hline \multicolumn{5}{|l|}{$\mathrm{UICR}^{\dagger}$} \\
\hline Quartile 1 & Reference & & Reference & \\
\hline Quartile 2 & $1.45(0.63-3.37)$ & 0.921 & $1.40(0.59-3.29)$ & 0.445 \\
\hline Quartile 3 & $1.34(0.64-2.80)$ & 0.621 & $1.31(0.61-2.81)$ & 0.493 \\
\hline Quartile 4 & $2.52(1.30-4.88)$ & $<0.001$ & $2.67(1.35-5.26)$ & 0.005 \\
\hline \multicolumn{5}{|c|}{$\begin{array}{l}\text { Intake of seaweed soup after } \\
\text { delivery }\end{array}$} \\
\hline No & Reference & & & \\
\hline Yes & $1.30(0.80-2.13)$ & 0.293 & & \\
\hline \multicolumn{5}{|c|}{$\begin{array}{l}\text { Duration of seaweed soup } \\
\text { consumption after childbirth }\end{array}$} \\
\hline Less than 1 week & Reference & & Reference & \\
\hline 1 week & $2.61(1.39-4.89)$ & 0.002 & $1.89(0.79-4.50)$ & 0.004 \\
\hline $1-2$ weeks & $1.30(0.70-2.42)$ & 0.683 & $0.87(0.36-2.13)$ & 0.870 \\
\hline 2-3 weeks & $0.70(0.32-1.55)$ & 0.132 & $0.44(0.17-1.11)$ & 0.064 \\
\hline 3-4 weeks & $0.93(0.47-1.85)$ & 0.441 & $0.68(0.30-1.56)$ & 0.511 \\
\hline $4-8$ weeks & $0.91(0.20-4.11)$ & 0.704 & $0.54(0.10-2.84)$ & 0.541 \\
\hline More than 8 weeks & $1.43(0.30-6.87)$ & 0.765 & $1.00(0.17-6.10)$ & 0.796 \\
\hline
\end{tabular}

${ }^{*}$ Data are presented OR $(95 \% \mathrm{Cl})$, Statistics were carried out using Logistic regression; ${ }^{\dagger}$ lodine intake status was evaluated by urine iodine creatinine ratio, UICR, Quartile 1: $<Q 1$ (141.5), Quartile 2: $\geq Q 1$ and $<Q 2$ (281.8), Quartile 3: $\geq Q 2$ and $<Q 3$ (664.6), Quartile 4: $\geq$ Q3.

was consumed within 1 week after birth, the OR was increased in the crude model (OR 2.61, Cl: 1.39-4.89, $p=0.002$ ), but this was no longer significant in the adjusted model (OR 1.89, Cl: 0.79-4.50) (Table 2).

\section{Discussion}

This study evaluated the association between the history of excessive seaweed intake after childbirth and $\mathrm{SCH}$ occurrence in Korean women based on the most recently released nationally representative data. In Korean women, seaweed soup intake after childbirth was not significantly related to $\mathrm{SCH}$ occurrence.

$\mathrm{SCH}$ is known to be a risk factor for cardiovascular disease, ${ }^{16-18)}$ especially for vascular calcification. ${ }^{19,20)}$ Therefore, treatment is recommended for those who have cardiovascular diseases. ${ }^{21)}$
Most studies have reported that age, presence of TPOAb, female sex, and high iodine intake are risk factors for $\mathrm{SCH}^{7)}$ Vadiveloo et al. $^{22)}$ analyzed data of 153,127 participants and found that the median TSH concentration increased with age. The US National Health and Nutrition Examination Survey III reported a trend toward a higher prevalence of $\mathrm{SCH}$ in individuals positive for TPOAb. ${ }^{2)}$ The Whickham survey reported that the risk of developing overt hypothyroidism was four times higher in individuals positive for TPOAb. ${ }^{23)}$ lodine intake is another risk factor for $\mathrm{SCH}$. Excessive iodine intake alters thyroid function through direct toxic effects or immunological alterations. ${ }^{24)}$

Australia's New South Wales (NSW) government has officially warned that seaweed soup is harmful to mothers and newborns because it contains excessive iodine. ${ }^{25)}$ Korean women traditionally consume brown seaweed soup (Undaria pinnatifida), called "Miyeok 
Guk", daily during the early postpartum period to increase breast milk production. According to the NSW government, dried seaweed soup contains $9000 \mu \mathrm{g}$ of iodine per $100 \mathrm{~g}$ of seaweed, which is $>33$ times the recommended daily intake. ${ }^{25)}$ Benotti et al. ${ }^{26)}$ measured the amount of iodine content in dried seaweed soup spectrophotometrically and suggested that 1 bowl (250 mL) of seaweed broth contains an average of $487 \pm 178 \mu \mathrm{g}$ of iodine. Korean women consume seaweed soup at least three times daily in the first postpartum week. ${ }^{27)}$ Rhee et al. ${ }^{28)}$ reported that Korean women consume on average at least 1400 $\mu \mathrm{g} /$ day of iodine in the first postpartum week, which was calculated based on the consumption of $250 \mathrm{~mL}$ of seaweed soup broth three times daily. Given that the World Health Organization (WHO) guidelines recommend $250 \mu \mathrm{g} /$ day (upper limit of $500 \mu \mathrm{g} /$ day) of iodine intake during pregnancy and lactation, Korean women seem to be consuming excess iodine during the postpartum period. ${ }^{27)}$ Our study clarifies if seaweed soup intake during the postpartum period is related to the occurrence of $\mathrm{SCH}$. In the crude model, the intake of seaweed soup within the first postpartum week seemed to increase the risk of $\mathrm{SCH}$ in mothers, but this association was no longer significant in the adjusted model.

The mechanism to explain this apparent lack of association between $\mathrm{SCH}$ risk and intake of seaweed soup is unclear. The effects of excessive iodine are dependent on several factors, including an underlying thyroid disease, thyroid autoimmunity, and the iodine levels before iodine exposure. ${ }^{28)}$ Although the thyroid gland is the main reservoir for iodine, breast and cervical tissues are also involved in iodine storage, ${ }^{29)}$ thus causing women to store excess iodine. Even if iodine is absorbed excessively, it can be stored in each tissue to some extent to prevent any harmful effects of excessive iodine intake. Possibly, $\mathrm{SCH}$ develops only when a certain threshold of iodine intake is exceeded. Changes in the breast and cervix associated with pregnancy may increase the capacity for iodine storage.

Our study has several limitations. First, it was a cross-sectional study; therefore, our results do not prove causality. Second, the data were self-reported because of the nature of the questionnaire-based research. The presence of medical illness and a detailed history of treatment were assessed based on the information provided by the participants. Third, due to the nature of data acquisition, the amount of iodine in seaweed soup was not quantified. Based on the results of a previous study on Korean individuals, it is estimated that about $1400 \mu \mathrm{g} /$ day of iodine was consumed after childbirth. ${ }^{28)}$ Additional quantitative analysis of the iodine content in seaweed soup is necessary.

This study has shown that the seaweed soup commonly consumed by Korean women does not have a significant effect on SCH occurrence, and that, although the duration of intake during postpartum is long, the effect is not significant. In a prospective study of the effects of excessive iodine on postpartum thyroiditis in Korean mothers, it was reported that intake of seaweed soup did not affect the incidence of postpartum thyroiditis. ${ }^{30)}$ Therefore, the NSW recommendation should be interpreted only as a warning that excessive seaweed soup intake will possibly result in thyroid dysfunction in Korean postpartum women. In the present study, seaweed soup consumption for even more than 8 weeks did not affect the occurrence of $\mathrm{SCH}$ in Korean women. Excessive concern about Korea's tradition of postpartum care with seaweed soup is not appropriate. However, individuals within the Korean population may have different responses to iodine consumption depending on the presence of autoimmune markers and the residential area. Further research is needed to determine whether these results are characteristic only to Korean women and if they differ depending on the ethnicity or residential area.

To our knowledge, this is the first study to investigate the association between the duration of seaweed soup consumption and the occurrence of $\mathrm{SCH}$ in Korean women who commonly consume seaweed soup during the postpartum period. Our analysis of population-based data showed that seaweed intake after childbirth and $\mathrm{SCH}$ occurrence may not be related. Further prospective studies are needed to de- 
Seaweed Soup and Subclinical Hypothyroidism

termine whether there is a causal relationship and the long-term outcomes of high iodine intake during the postpartum period.

\section{Conflict of Interest}

\section{The authors declare no conflict of interest.}

\section{References}

1) Cooper DS. Clinical practice. Subclinical hypothyroidism. $N$ Engl J Med 2001;345(4):260-5.

2) Hollowell JG, Staehling NW, Flanders WD, Hannon WH, Gunter EW, Spencer CA, et al. Serum TSH, T(4), and thyroid antibodies in the United States population (1988 to 1994): National Health and Nutrition Examination Survey (NHANES III). J Clin Endocrinol Metab 2002;87(2):489-99.

3) Kim WG, Kim WB, Woo G, Kim H, Cho Y, Kim TY, et al. Thyroid Stimulating Hormone Reference Range and Prevalence of Thyroid Dysfunction in the Korean Population: Korea National Health and Nutrition Examination Survey 2013 to 2015. Endocrinol Metab (Seoul) 2017;32(1):106-14.

4) Canaris GJ, Manowitz NR, Mayor G, Ridgway EC. The Colorado thyroid disease prevalence study. Arch Intern Med 2000;160(4):526-34.

5) Aghini-Lombardi F, Antonangeli L, Martino E, Vitti P, Maccherini D, Leoli F, et al. The spectrum of thyroid disorders in an iodine-deficient community: the Pescopagano survey. J Clin Endocrinol Metab 1999;84(2):561-6.

6) Laurberg P, Pedersen KM, Hreidarsson A, Sigfusson N, Iversen E, Knudsen PR. Iodine intake and the pattern of thyroid disorders: a comparative epidemiological study of thyroid abnormalities in the elderly in Iceland and in Jutland, Denmark. J Clin Endocrinol Metab 1998;83(3):765-9.

7) Kim YA, Park YJ. Prevalence and risk factors of subclinical thyroid disease. Endocrinol Metab (Seoul) 2014;29(1):20-9.

8) Konno N, Makita $H$, Yuri $K$, Iizuka $N$, Kawasaki $K$. Association between dietary iodine intake and prevalence of subclinical hypothyroidism in the coastal regions of Japan. J Clin Endocrinol Metab 1994;78(2):393-7.

9) Kim JY, Moon SJ, Kim KR, Sohn CY, Oh JJ. Dietary iodine intake and urinary iodine excretion in normal Korean adults. Yonsei Med J 1998;39(4):355-62.

10) WHO, UNICEF, ICCIDD. Assessment of iodine deficiency disorders and monitoring their elimination: A guide for programme managers. 3rd ed. Geneva: World Health Organization; 2007.

11) Cho YY, Kim HJ, Oh SY, Choi SJ, Lee SY, Joung JY, et al. Iodine status in healthy pregnant women in Korea: a first report. Eur J Nutr 2016;55(2):469-75.

12) Lee SH, Han K, Yang HK, Kim HS, Cho JH, Kwon HS, et al. A novel criterion for identifying metabolically obese but normal weight individuals using the product of triglycerides and glucose. Nutr Diabetes 2015;5(4):e149.

13) Tran BT, Jeong BY, Oh JK. The prevalence trend of metabolic syndrome and its components and risk factors in Korean adults: results from the Korean National Health and Nutrition Examination Survey 2008-2013. BMC Public Health 2017;17(1):71.

14) Kim J. Association between serum vitamin D, parathyroid hormone and metabolic syndrome in middle-aged and older Korean adults. Eur J Clin Nutr 2015;69(4):425-30.

15) Baloch Z, Carayon P, Conte-Devolx B, Demers LM, Feldt-Rasmussen U, Henry JF, et al. Laboratory medicine practice guidelines. Laboratory support for the diagnosis and monitoring of thyroid disease. Thyroid 2003;13(1):3-126.

16) Suh S, Kim DK. Subclinical hypothyroidism and cardiovascular disease. Endocrinol Metab (Seoul) 2015;30(3):246-51.

17) Luboshitzky R, Aviv A, Herer P, Lavie L. Risk factors for cardiovascular disease in women with subclinical hypothyroidism. Thyroid 2002;12(5):421-5.

18) Walsh JP, Bremner AP, Bulsara MK, O'Leary P, Leedman $\mathrm{PJ}$, Feddema $\mathrm{P}$, et al. Subclinical thyroid dysfunction as a risk factor for cardiovascular disease. Arch Intern Med 2005;165(21): 2467-72.

19) Hak AE, Pols HA, Visser TJ, Drexhage HA, Hofman A, Witteman JC. Subclinical hypothyroidism is an independent risk factor for atherosclerosis and myocardial infarction in elderly women: the Rotterdam Study. Ann Intern Med 2000;132(4):270-8.

20) Ichiki T. Thyroid hormone and atherosclerosis. Vascul Pharmacol 2010;52(3-4):151-6.

21) Surks MI, Ortiz E, Daniels GH, Sawin CT, Col NF, Cobin $\mathrm{RH}$, et al. Subclinical thyroid disease: scientific review and guidelines for diagnosis and management. JAMA 2004;291(2): 228-38.

22) Vadiveloo T, Donnan PT, Murphy MJ, Leese GP. Age- and gender-specific TSH reference intervals in people with no obvious thyroid disease in Tayside, Scotland: the Thyroid Epidemiology, Audit, and Research Study (TEARS). J Clin Endocrinol Metab 2013;98(3):1147-53.

23) Vanderpump MP, Tunbridge WM, French JM, Appleton D, Bates D, Clark F, et al. The incidence of thyroid disorders in the community: a twenty-year follow-up of the Whickham Survey. Clin Endocrinol (Oxf) 1995;43(1):55-68.

24) Mahmoud I, Colin I, Many MC, Denef JF. Direct toxic effect of iodide in excess on iodine-deficient thyroid glands: epithelial necrosis and inflammation associated with lipofuscin accumulation. Exp Mol Pathol 1986;44(3):259-71.

25) Government NSW. Warning for pregnant and breastfeeding women. 2011 [cited July 17, 2019]. Available from: http://www.mhcs.health.nsw.gov.au/publicationsandresources/pdf/ publication-pdfs/9120/ahs-9120-eng.pdf/view.

26) Benotti J, Benotti N, Pino S, Gardyna H. Determination of total iodine in urine, stool, diets, and tissue. Clin Chem 1965; 11(10):932-6.

27) Moon S, Kim J. Iodine content of human milk and dietary iodine intake of Korean lactating mothers. Int J Food Sci Nutr 1999;50(3):165-71.

28) Rhee SS, Braverman LE, Pino S, He X, Pearce EN. High iodine content of Korean seaweed soup: a health risk for lactating women and their infants? Thyroid 2011;21(8):927-8.

29) Ahad F, Ganie SA. Iodine, Iodine metabolism and Iodine 
Hyunsam Kim, et al

deficiency disorders revisited. Indian J Endocrinol Metab 2010; 14(1):13-7.

30) Kim WB, Alavi A, Walsh S, Pope E. Reply to Frane: epidermolysis bullosa pruriginosa: a systematic review exploring genotype-phenotype correlation. Am J Clin Dermatol 2015;16(4): 339. 
Seaweed Soup and Subclinical Hypothyroidism

Supplementary Table 1. Median TSH according to age group of Korean women

\begin{tabular}{cc}
\hline Age & Median $T S H(\mathrm{IU} / \mathrm{mL})$ \\
\hline $19-29$ & 2.37 \\
$30-39$ & 2.25 \\
$40-49$ & 2.20 \\
$50-59$ & 2.55 \\
$60-69$ & 2.26 \\
$70-$ & 2.66 \\
\hline
\end{tabular}

TSH: thyroid stimulating hormone 